Gdańsk 2019, Nr. 41

https://doi.org/10.26881/sgg.2019.41.21

Marta Śleziak

Instytut Filologii Polskiej, Uniwersytet Wrocławski

Institut für Polnische Philologie, Universität Wrocław

https://orcid.org/0000-0003-4297-7728

\title{
„Lesen und weitergeben“. Ephemere Drucke vor der Volksabstimmung in Oberschlesien (1921) als Beispiel einer effektiven Kommunikation
}

Der Beitrag setzt sich mit ephemeren Drucken auseinander, die vor der Volksabstimmung in Oberschlesien 1921 gedruckt und verbreitet wurden und heute in der Universitätsbibliothek der Universität Wrocław aufbewahrt werden. Die Flugblätter und Anschlagzettel aus diesem Korpus werden als besonders wirkungsmächtige Medien charakterisiert, die mit größter Sorgfalt und meist in zwei Sprachen (Deutsch und Polnisch) vorbereitet wurden. Ihre Wirksamkeit verdanken sie Faktoren wie den historischen und gesellschaftlichen Umständen ihrer Entstehung, ihren gattungsmäßigen und stilistischen Merkmalen sowie ihrem breiten Wirkungskreis.

Schlüsselwörter: Ephemera, Volksabstimmung in Oberschlesien 1921, Aufstände in Oberschlesien, Persuasion

"Read and pass it on". Ephemera printed before Upper Silesia plebiscite (1921) as an example of effective communication. - The paper analyzes ephemera printed before Upper Silesia plebiscite (1921), collected in Wroclaw University Library. Plebiscitary leaflets, written in Polish and German, are characterized as good-featured and effective media. Not only the social background of the analyzed ephemera but also their genres, stylistics and massive coverage had a great impact on their effective persuasion.

Keywords: ephemera, Upper Silesia plebiscite, Silesian uprisings, persuasion

\section{Vorbemerkung und Darstellung des Korpus}

Die Volksabstimmung in Oberschlesien am 20. März 1921 war der Höhepunkt des Konflikts um die südliche Grenze Polens nach dem Ersten Weltkrieg. Im Zuge des Versailler Vertrags wurde auf einem Teil des umstrittenen Territoriums zwischen Polen und Deutschland ein Abstimmungsgebiet festgelegt, über dessen Zugehörigkeit (zu Deutschland oder zu Polen) die Bevölkerung in einem Plebiszit entscheiden sollte. Das Gebiet umfasste die Städte: Beuthen (Bytom), Gleiwitz (Gliwice), Kattowitz (Katowice), Königshütte (Chorzów), Oppeln (Opole), Ratibor (Racibórz), sowie die Landkreise: Beuthen, Leobschütz (Głubczyce), Kattowitz, Kreuzburg (Kluczbork), Cosel (Koźle), Lublinitz bzw. Loben (Lubliniec), Oels 
(Oleśnica), Oppeln, den östlichen Teil des Landkreises Neustadt O.S. (Prudnik), die Landkreise: Pszczyna (Pless), Ratibor, Rybnik, Groß Strehlitz (Strzelce Opolskie), Tost-Gleiwitz (Toszek-Gliwice), Zabrze und den östlichen Teil des Landkreises Namslau (Namysłów). Auf dem so abgesteckten Gebiet galt nach wie vor die deutsche Verwaltung, auch die deutsche Polizei war dort tätig, während sich die deutschen Truppen bereits zurückgezogen hatten (vgl. Goniewicz 2001: 15). Insgesamt betraf das Plebiszit rund 2,2 Mio. Menschen.

Für die Angliederung an das wiedergegründete Polen votierten 40,3\%, für einen Verbleib in Deutschland 59,4\% der Wähler. Bald nach der Entscheidung des Plebiszits, in der Nacht vom 2. auf den 3. Mai 1921, brach der dritte Aufstand in Oberschlesien aus. Das Plebiszit bzw. der Streit um dessen Ergebnis hat zum Ausbruch des Aufstands wesentlich beigetragen.

Sowohl dem Plebiszit von 1921 als auch den drei Aufständen in Oberschlesien (1919, 1920 und 1921) sind viele historische Studien gewidmet. ${ }^{1}$ Von Historikern wurde diese Problematik komplex unter politischen, wirtschaftlichen, sozialen und national-ethnischen Aspekten dargestellt, wobei die Frage der nationalen Minderheiten in den Vordergrund rückte. Aus literaturwissenschaftlicher Perspektive wird hingegen untersucht, wie die Autoren, die diese historischen Ereignisse in ihren literarischen Texten thematisieren, durch Bezüge zum literarischen Kanon sowie durch den Einsatz satirischer Mittel an der Bildung der nationalen Gemeinschaft mitwirkten. ${ }^{2}$

Abgesehen von politischen Fragen, die bereits tiefgehenden Analysen unterzogen wurden, empfiehlt es sich, einen der wesentlichen Aspekte des Konflikts um das Abstimmungsergebnis in den Blick zu nehmen. Denn das für den 20. März 1921 geplante Plebiszit war Gegenstand einer besonders intensiven Kampagne, in deren Rahmen zahlreiche ephemere Drucke entstanden. Die vielfältige Gestalt dieser Ephemera, ihre Anzahl, Erscheinungsfrequenz, vor allem aber die darin vermittelten propagandistischen Inhalte sind für die heutige Forschung eine kaum zu überschätzende Quelle von Wissen über die hier interessierenden historischen Ereignisse. Flugblätter und Anschlagzettel waren die populärsten Medien, mit denen am Vorabend der Volksabstimmung eine breite Öffentlichkeit erreicht werden konnte:

„[Flugblätter und Anschlagzettel] wurden meistens auf herkömmlichen Wegen verbreitet; die Deutschen warfen sie auch von Flugzeugen ab. Der Massencharakter dieser dem Plebiszit vorausgegangenen Propagandaform bewirkte, dass man - so die Aktivisten, die sich in den Abstimmungskampf engagierten - auf den Straßen bis an die Knöchel in Fetzen von Flugblättern waten musste, zumal diese oft auf unbeständigem Zeitungspapier gedruckt wurden.“ (EPŚ 1982: 584$)^{3}$

\footnotetext{
1 Hingewiesen sei hier auf einige bedeutende Monographien (LIs / DróżDż 2012), Besprechungen in historischen Synthesen (CzU BIŃSKI 2002: 102-105), Einträge in der Encyklopediapowstań śląkich [Enzyklopädie der Aufstände in Oberschlesien] (EPŚ) sowie auf die Beschreibung dieser Ereignisse aus der gegenwärtigen Perspektive (Lis 2015). Eine systematische Darstellung der vor dem Plebiszit eingesetzten Propagandamittel sowie eine Charakteristik der oberschlesischen Presse zur Zeit der Volksabstimmung hat ZielińsKi (1972) vorgenommen.

2 Heska-Kwaśniewicz (1999) nimmt poetische Texte unter die Lupe, die der Prägung des nationalen Bewusstseins dienen sollten. Viel Aufmerksamkeit widmet sie der Satire, die insbesondere in der oberschlesischen „Kocynder“ - einer populären humoristischen Monatsschrift, die seit Juni 1920 erschien - publiziert wurde.

3 Übersetzungen von Zitaten aus der angeführten Sekundärliteratur in polnischer Sprache stammen von der Übersetzerin dieses Beitrags.
} 
Mit der Poetik der polnischen Flugblätter, die vor der Volksabstimmung gedruckt wurden, beschäftigt sich HESKA-KWAŚNIEWICZ (2006). Sie weist auf eine volkstümliche, gleichsam mythische Sicht der Welt hin, die in den Flugblättern zum Ausdruck kommt: Die Realität wird hier in Gut und Böse gespalten, die Menschen werden in „eigene “ und „fremde“ eingeteilt. Die polnische Seite wird mithilfe von suggestiven Argumenten (Anführung statistischer Daten, die Polen in einem positiven Licht erscheinen lassen, häufige Anspielungen auf die katholische Tradition) in jeder Hinsicht idealisiert. Zum Einsatz kommen wirkungsvolle verbale und visuelle Mittel: stilistische (u.a. stark abwertende Epitheta in Bezug auf die Deutschen) und graphische (Abbildungen, die die verbale Charakteristik der Widersacher ergänzen) (vgl. HesKa-Kwaśniewicz 2006: 103-111). Das von Heska-Kwaśniewicz ausgewertete Material stammt aus der Schlesischen Bibliothek in Katowice. Auch Aleksander DrozdowsKI (2001), der sich mit deutschen Ephemera aus der Zeit vor dem Plebiszit auseinandersetzt, zieht in seiner Analyse Ephemera aus den Sammlungen dieser Bibliothek heran. Drozdowski stellt die Merkmale heraus, die für sein Korpus besonders charakteristisch sind, und kommt zum Schluss, dass in den ephemeren Drucken folgende Motive am häufigsten auftreten: die Darstellung Schlesiens als integraler Bestandteil von Deutschland; Kritik der Armut und Rückständigkeit der polnischen Wirtschaft; Bewusstmachung der ungenügenden Leistungsfähigkeit des polnischen Staates im sozialen Bereich (vgl. DrozDowsKi 2001:36-38). In den deutschen Flugblättern erkennt Drozdowski dieselben Eigenschaften, die Heska-Kwaśniewicz in den polnischen Drucken identifiziert hat: ein häufiges Heranziehen statistischer Daten, die Betonung religiöser Elemente (der „traditionellen schlesischen Religiosität“) und die Zusammenstellung von zwei Sprachversionen der Texte, durch die der potentielle Adressatenkreis erweitert wird. ${ }^{4}$

Im vorliegenden Beitrag beschreibe ich die mit der oberschlesischen Volksabstimmung verbundenen Ephemera, die sich in den Sammlungen der Universitätsbibliothek der Universität Wrocław befinden. Ich berücksichtige sowohl die polnisch- als auch die deutschsprachigen Drucke und betrachte sie im Hinblick auf ihre Gattungszugehörigkeit, ihre Formen sowie die Sprachmittel, deren sich ihre Autoren bedienen. Dabei stelle ich folgende Forschungsfragen: Was ist die Spezifik des ausgewerteten Korpus? Sind die Drucke der beiden Parteien ähnlich, was ihre Form und ihren Stil anbelangt? Ich greife dabei auf die Erkenntnisse der vorgenannten Autoren zurück, die jeweils nur die deutschen bzw. nur die polnischen Ephemera untersucht haben. Wie die Analysen von Drozdowski und von Heska-Kwaśniewicz zeigen, ist eine

4 „Während derartige [d.h. zweisprachige, M. Ś.] Flugblätter die gesamte Bevölkerung Oberschlesiens zur Stimmabgabe für Deutschland anspornen sollten, gab es auch Flugblätter, die sich ausschließlich an die deutschen Bewohner richteten [...]. Diese Drucke machten jedoch die Minderheit aus, weil den Deutschen bewusst war, dass die polnischsprachige Bevölkerung auf dem Abstimmungsgebiet der deutschsprachigen zahlenmäßig überlegen ist" (DrozDowski 2001: 41). Die Rolle von Ephemera für die beiden Streitparteien stellt ZIELIŃSKI (1972) heraus: „Flugblätter und Plakate wurden allgemein wahrgenommen, da sie die populärsten und massenweise eingesetzten Propagandamittel sind; sie verwenden stark verkürzte Texte und Illustrationen, die die Eigenschaften des Widersachers in einem negativen Lichte darstellen. Somit haben Flugblätter und Plakate dazu beigetragen, dass negative Stereotype der Polen und der Deutschen in der Öffentlichkeit intensiv verbreitet wurden - Stereotype, die von dem deutschen genauso wie von dem polnischen Plebiszitkommissariat lanciert wurden und die in erster Linie nationalistische Stimmungen befeuerten." (ZIELIŃSKI 1972: 106) 
gewisse Ähnlichkeit im Hinblick auf die Anwendung bestimmter Motive in den deutschen und polnischen Drucken erkennbar; es bleibt dennoch zu erörtern, ob es auf der Ebene der Textkomposition und der Stilistik ebenfalls Analogien gibt.

Mein Korpus umfasst 165 ephemere Drucke, die vor der Volksabstimmung in Oberschlesien verbreitet wurden. ${ }^{5}$ Darin sind enthalten: 59 propolnische Drucke (darunter 21 ein- und 38 zweisprachige) und 106 prodeutsche Drucke (darunter 54 ein- und 52 zweisprachige). In der Gruppe der einsprachigen propolnischen Drucke sind die meisten Texte auf Polnisch und sieben auf Deutsch verfasst worden. In der Gruppe der einsprachigen prodeutschen Drucke gibt es nur vier Texte in polnischer und einen Text in tschechischer Sprache.

In den beiden zweisprachigen Gruppen (der propolnischen und der prodeutschen) sind die Texte auf Polnisch und auf Deutsch jeweils entweder parallel in zwei Spalten (vgl. Abb. 1) oder auf der Vorder- und Rückseite desselben Blattes gedruckt worden.

Tabellarisch lässt sich die Charakteristik des Korpus wie folgt darstellen:

\begin{tabular}{|l|c|c|}
\hline & Propolnische Ephemera & Prodeutsche Ephemera \\
\hline Einsprachig & $\begin{array}{c}21 \\
54 \\
14-\text { auf Polnisch } \\
7-\text { auf Deutsch }\end{array}$ & $\begin{array}{c}49-\text { auf Deutsch } \\
4-\text { auf Polnisch } \\
1-\text { auf Tschechisch }\end{array}$ \\
\hline $\begin{array}{l}\text { Zweisprachig (Deutsch / } \\
\text { Polnisch) }\end{array}$ & 38 & 52 \\
\hline Insgesamt & 59 & 106 \\
\hline & \multicolumn{2}{|c|}{165} \\
\hline
\end{tabular}

Unmittelbar vor der Volksabstimmung waren ephemere Drucke ein bedeutsames kommunikatives Mittel für die oberschlesische Bevölkerung. Wegen ihrer enormen Auflagenstärke (bis zu mehreren hunderttausend Exemplaren, vgl. EŚP 1982: 583) sowie aufgrund der zweisprachigen Textaufbereitung hatten die damaligen Ephemera einen sehr breiten Wirkungskreis. Es dominiert in ihnen eine informative Funktion, die sich an der problemzentrierten Darstellung einzelner Fragen bemerkbar macht (d.h., in den meisten Fällen ist jedes Flugblatt einem einzelnen Problem gewidmet), daher erinnern die Flugblätter an massenhaft kopierte Zeitungsartikel; diese Ähnlichkeit ist u.a. der Textanordnung im Spaltensatz zu verdanken. Außerdem gibt es Querverweise zwischen den einzelnen Drucken: Sie beziehen sich aufeinander, reagieren teils polemisch auf die Texte der Gegenpartei. Dies macht die plebiszitären

5 Die hier angeführten und analysierten Drucke gehören zur Sammlung von Ephemera der SchlesischSorbischen Abteilung (Gabinet Śląsko-Łużycki) der Universitätsbibliothek der Universität Wrocław. Die Bestände an plebiszitären Drucken werden immer noch erschlossen und die Sammlung wird laufend um weitere Exemplare ergänzt, die in den Magazinen der Bibliothek sortiert und bearbeitet werden. Die das Plebiszit betreffenden Drucke sind in zwei Gruppen eingeteilt: „Plebiscyt na Górnym Śląsku. Afisze i ulotki propagandowe propolskie” [,Die Volksabstimmung in Oberschlesien. Propolnische Anschlagzettel und Propaganda-Flugblätter'] sowie „Plebiscyt na Górnym Śląsku. Afisze i ulotki propagandowe proniemieckie” [,Die Volksabstimmung in Oberschlesien. Prodeutsche Anschlagzettel und Propaganda-Flugblätter']. Eine detaillierte Beschreibung der einzelnen Drucke ist im Online-Katalog der Universitätsbibliothek der Universität Wrocław zu finden, abrufbar

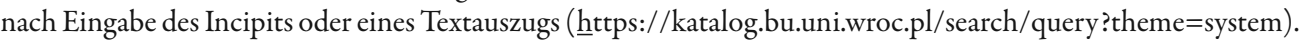




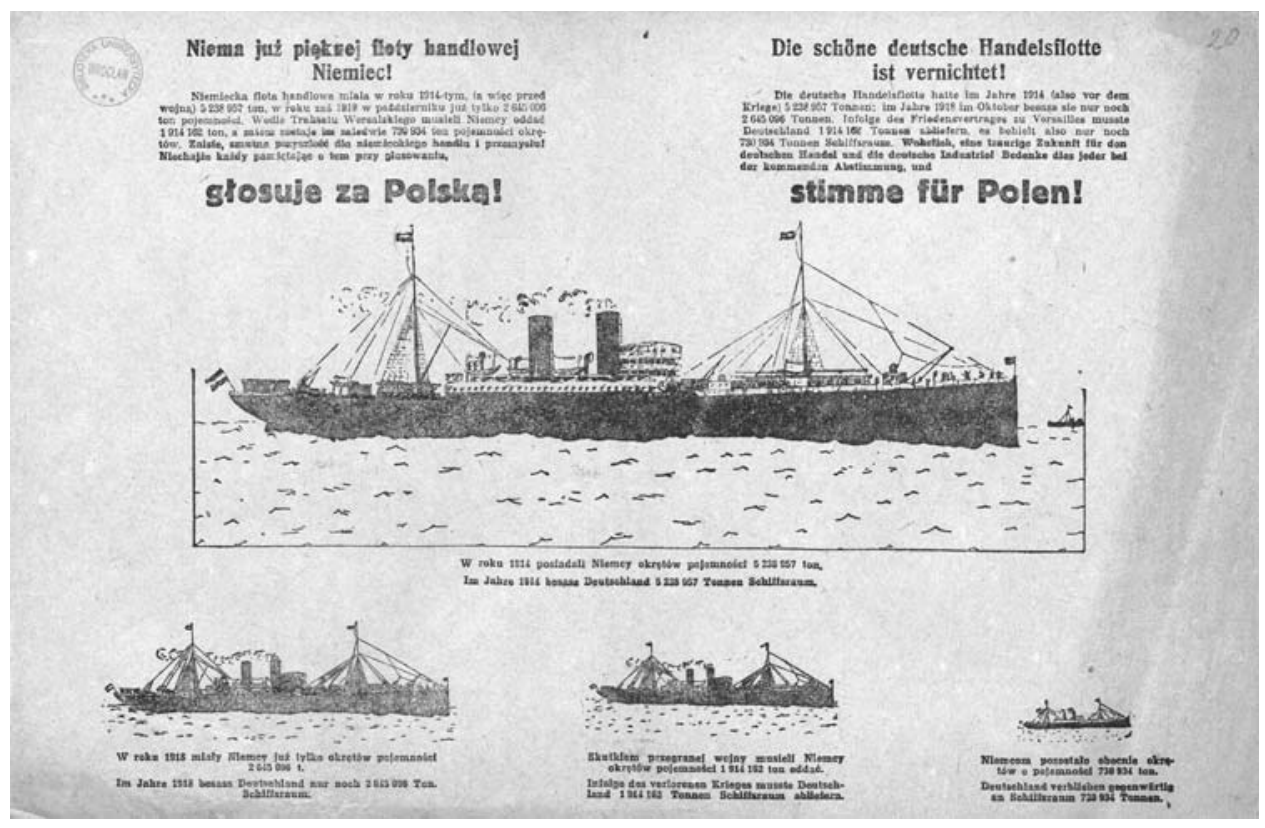

Abb. 1. Flugblatt „Niema już pięknej floty handlowej Niemiec! / Die schöne deutsche Handelsflotte ist vernichtet!“

Drucke zu bedeutsamen Medien mit einem hohen Erkenntniswert und einem kaum zu überschätzenden Einfluss auf ihre Rezipienten.

Es bleibt noch ein Merkmal zu erwähnen, das viele Ephemera kennzeichnet, die aus Anlass von wichtigen Ereignissen entstehen - mag es sich dabei um lokal bedeutsame Veranstaltungen oder um große nationale Erhebungen handeln. Derartige Ephemera - ausgenommen etwa Bekanntmachungen und ähnliche Schriften mit rein informativem Charakter - halten die gesellschaftlichen Stimmungen, Einstellungen und Emotionen derjenigen Personen fest, die an der Abfassung der ephemeren Texte beteiligt sind. Somit stellt die Lektüre von Ephemera auch einen Zugang zu den zeitgenössischen Wahrnehmungen von vergangenen Ereignissen her.

Nicht ohne Grund weist Józef KrZyK (2014) in seiner Studie über Plakate aus der Zeit der schlesischen Aufstände auf die Rolle von Emotionen hin. In seiner Einleitung erwähnt der Autor das Museum der Schlesischen Aufstände im heutigen Świętochłowice (Schwientochlowitz), in dem viele Ephemera aus dieser Zeit gesammelt sind. An seine Reflexion über die Gestaltung der Museumsausstellung schließt er folgende Bemerkung an:

„Was hier jedoch am meisten interessiert, sind die Drucke: Propaganda-Plakate der beiden verfeindeten Parteien, Fotografien, Flugblätter und Zeitungen. Es genügt, einen Augenblick bei ihnen zu verweilen, um die Emotionen zu empfinden, die die Menschen damals bewegten; man gerät dadurch genau in den Mittelpunkt des um Oberschlesien ausgetragenen ,Papierkriegs.“ (KRZYK 2014: 3)

Damit bringt der Autor das wichtigste Wesensmerkmal ephemerer Drucke auf den Punkt: Als Medien vermitteln sie nämlich nicht nur Informationen über das betreffende Ereignis, sondern sie spiegeln auch die Stimmungen, die dieses Ereignis begleiteten, wider. In der materiellen 
Beschaffenheit von Flugblättern und Anschlagzetteln - in ihrer Grammatur, in der Art und Weise, wie die Papieroberfläche bedruckt ist, in der Anzahl der gedruckten Exemplare - werden die Umstände ihrer Entstehung erkennbar, wenn auch nur indirekt und aus historischer Distanz. In ihrem Inhalt wiederum manifestieren sich die sprachlich ausgedrückten Emotionen, Wertvorstellungen und Haltungen, die für die Autoren der jeweiligen Botschaft charakteristisch sind. Darüber hinaus lassen die mit viel graphischem Aufwand gestalteten Plakate und Flugschriften die Bemühung erkennen, die Dominanz einer bestimmten Gruppe symbolisch darzustellen. ${ }^{6}$ Ephemere Drucke stehen den metaphorisch aufgefassten ,heißen" Medien nahe, die einen bestimmten Sinn - hier: den visuellen - besonders ansprechen (STM 117); sie vermitteln Informationen schnell und auf emotionalem Wege. All diese Eigenschaften zeigen, dass die hier untersuchten ephemeren Drucke eine mächtige Waffe im Streit um die Zugehörigkeit Oberschlesiens darstellten.

\section{Zur Gattungszugehörigkeit der plebiszitären Drucke}

Bevor die hier vorgestellten Ephemera näher charakterisiert werden, ist vorauszuschicken, dass das erschlossene Korpus eine große Vielfalt von Gattungen abdeckt. Es überwiegen Aufrufe an die Oberschlesier, die direkt dazu auffordern, für die Zugehörigkeit zu Polen (propolnische Drucke) bzw. zu Deutschland (prodeutsche Drucke) zu votieren. Man kann diese Texte schwerlich als Bekanntmachungen einstufen, da sie weder den für dieses Genre typischen Textrahmen aufweisen noch die entsprechende Gattungsbezeichnung im Titel führen. Autoren der oberschlesischen Aufrufe, Mitteilungen und Benachrichtigungen sprechen ihre Rezipienten unmittelbar an entweder bereits in der Überschrift oder in weiteren Passagen des Textes. Am häufigsten sind Anreden an bereits im Voraus festgelegte Zielgruppen:

In prodeutschen zweisprachigen Drucken: ${ }^{7}$

\begin{tabular}{|l|l|}
\hline \multicolumn{1}{|c|}{ Polnisch } & \multicolumn{1}{c|}{ Deutsch } \\
\hline „Górnośląscy rolnicy!“ & „Oberschlesische Bauern!" \\
\hline „Górnoślązacy!“ & "Oberschlesier!" \\
\hline „Baczność! Do kaleków wojennych i ich pozostałych!” & $\begin{array}{l}\text { „Achtung! Achtung! Oberschlesische Kriegsbeschä- } \\
\text { digte und Hinterbliebene!“ }\end{array}$ \\
\hline
\end{tabular}

6 Die Autoren der Encyklopediapowstań ślaskich [Enzyklopädie der Aufstände in Oberschlesien] bemerken, dass die graphischen Elemente der Plakate ihren Autoren die Chance bieten, die jeweiligen Widersacher effektiv anzugreifen und die Rezipienten zu erreichen, die von der allgegenwärtigen Propaganda bereits ermüdet waren (vgl. EŚP 393).

7 Zitate aus zweisprachigen, d.h. auf Polnisch und auf Deutsch abgefassten Drucken stehen jeweils in einer Tabelle, wobei der polnische und der deutsche Text zwei Parallelfassungen darstellen; welche davon ursprünglich das Original und welche die Übersetzung war, lässt sich heute nicht mehr entscheiden. In einigen Fällen weichen der polnische und der deutsche Text voneinander ab, worauf hier allerdings nicht eingegangen wird. Im laufenden Text des Beitrags wird i.d.R. zunächst die polnische und dann die deutsche Fassung des zweisprachigen Flugblatts zitiert, ggf. mit dem Vermerk „dt. Parallelfassung“. Bei einsprachigen polnischen Drucken ohne deutsche Parallelversion wird in Eckklammern und einfachen Anführungszeichen ['] die sinngemäße deutsche Übersetzung angegeben und auch explizit als solche genannt. 


\begin{tabular}{|l|l|}
\hline „Do robotników górnośląskich“ & "An die oberschlesischen Arbeite“" \\
\hline "Do wojowników górnośląskich!” & "An die oberschlesischen Krieger!“ \\
\hline
\end{tabular}

In propolnischen zweisprachigen Drucken:

\begin{tabular}{|l|l|}
\hline \multicolumn{1}{|c|}{ Polnisch } & \multicolumn{1}{c|}{ Deutsch } \\
\hline $\begin{array}{l}\text { "Do wszystkich bezrolnych, robotników rolnych, } \\
\text { służby folwarcznej i małorolnych na G. Śląsku!” }\end{array}$ & $\begin{array}{l}\text { "An alle Landlosen, Land- und Guts-Arbeiter und an } \\
\text { alle Kleinbauern in Oberschlesien!“ }\end{array}$ \\
\hline "Do ludu górnośląskiego!” & "An das oberschlesische Volk!“ \\
\hline
\end{tabular}

In propolnischen einsprachigen Drucken (nur auf Polnisch):

- „Górnicy! Rodacy!” [sinngemäße dt. Übers.: ,Bergmänner! Landsleute!'];

- „Polki Górnośląskie!” [sinngemäße dt. Übers.: ,Oberschlesische Polinnen!']

In den deutschen und polnischen Sprachversionen werden also die Anreden ähnlich formuliert. Allerdings wendet sich keines der Flugblätter an „die Polen“ oder „die Deutschen“, betont wird dagegen „das Oberschlesische“ der angesprochenen Gruppe. Interessanterweise enthalten Drucke, die nicht von lokalen Akteuren verfasst wurden, ${ }^{8}$ allgemeinere Wendungen, wie etwa: „Rodacy!“(sinngemäß: ,Landsleute!') in der Schrift von Wojciech Korfanty oder „Ślązacy“ (sinngemäß: ,Schlesier') im Text des Generals Józef Haller. Eine interessante Strategie, die Anrede zu formulieren, stellt der Appell an ,alle polnisch Denkenden und Fühlenden in Schlesien ' „Do wszystkich myślących i czujących na Śląsku po polsku”, nur auf Polnisch abgefasst) dar, der dem Leser einen individuellen interpretatorischen Freiraum offen hält.

Sämtliche Drucke, sowohl die propolnischen als auch die prodeutschen, zeichnen sich durch dichte Inhalte aus. Sie sind eng bedruckt, wobei vergrößerte, fettgedruckte oder unterstrichene Textpassagen einen besseren Überblick über den Text verschaffen sollen. Die Textkonstruktion lässt eine bestimmte Tendenz erkennen: Fragen, die das Thema des jeweiligen Flugblatts bilden, werden problematisiert, meistens durch eine Fragestellung in der Überschrift. Dieses Verfahren fällt häufiger in den prodeutschen Flugblättern auf, wie die folgenden Beispiele aus zweisprachigen Drucken veranschaulichen:

In zweisprachigen Drucken:

\begin{tabular}{|l|l|}
\hline \multicolumn{1}{|c|}{ Polnisch } & \multicolumn{1}{|c|}{ Deutsch } \\
\hline $\begin{array}{l}\text { „Czy Górny Śląsk rzeczywiście został tak bardzo } \\
\text { zaniedbany?” }\end{array}$ & „Ist Oberschlesien so sehr zurückgesetzt [sic!] worden?“ \\
\hline $\begin{array}{l}\text { „Czy kościół katolicki rzeczywiście został tak bardzo } \\
\text { zaniedbany?” }\end{array}$ & „Ist die katholische Kirche in Oberschlesien zurückge- \\
setzt [sic!] worden?”
\end{tabular}

8 Nicht alle hier berücksichtigten Drucke wurden von dem polnischen Plebiszitkommissariat mit Sitz in Beuthen (Bytom) signiert (und dort gedruckt). Der Aufruf von Józef Haller wurde in Warschau gedruckt. Die übrigen Flugblätter stammen u.a. aus Druckereien in Nikolai (Mikołów), Kattowitz und Gleiwitz. 


\begin{tabular}{|l|l|}
\hline "Czy my Górnoślązacy mamy się do Polski przyłączyć?” & "Sollen wir Oberschlesier uns an Polen anschließen?“ \\
\hline "Gdzie się rolnikowi lepiej powodzi - czy w Prusiech, & „Wo steht sich der Bauer besser: in Preussen oder in \\
czy w Polsce?” & Polen?“ \\
\hline $\begin{array}{l}\text { "Gospodarze Górnego Śląska! Czego się spodziewać } \\
\text { możecie, w razie gdybyśmy się dostali do Polski?” }\end{array}$ & „Landwirte Oberschlesiens! Was habt Ihr von einer \\
Angliederung an Polen zu erwarten?“"
\end{tabular}

Dieses rhetorische Verfahren wird in den propolnischen Schriften des vorliegenden Korpus weniger häufig angewandt. Die Überschriften der propolnischen Ephemera wirken dagegen mehr wie persuasive, emotionsbetonte Pressetitel:

In zweisprachigen Drucken:

\begin{tabular}{|l|l|}
\hline \multicolumn{1}{|c|}{ Polnisch } & \multicolumn{1}{|c|}{ Deutsch } \\
\hline „Co znaczy 226 miljard. marek w złocie?” & „Was bedeuten 226 Milliarden Goldmark?“ \\
\hline „Bandytyzm niemiecki na G.-Śl.” & „Der deutsche Banditismus [sic!] in Oberschlesien“ \\
\hline $\begin{array}{l}\text { „Magnaci niemieccy za Polską. Co mówią wybitni } \\
\text { Niemcy o przyszłości Górnego Śląska?” }\end{array}$ & „Markante Magnatenworte. Was denken deutsche \\
\hline „Rumunner über Oberschlesiens Zukunfte“
\end{tabular}

Unter den prodeutschen Ephemera finden sich auch Texte, die keine Entsprechungen im Textkorpus der Gegenpartei besitzen. Es handelt sich um Flugblätter mit Propagandasprüchen, Zitaten, rhetorischen Fragen oder Texten in gebundener Rede. Ephemere Drucke dieser Art wurden in kleineren Formaten als beispielsweise Mitteilungen gedruckt; die verwendete Schriftart ist dabei größer und dekorativer, während der Text oft eingerahmt ist. Erwähnenswert sind in dieser Gruppe von Drucken unter anderem Zitate von Maximilian Pfeiffer ${ }^{10}$ und Bernhard Dernburg ${ }^{11}$ (beiden Namen wird der Doktor-Titel vorangestellt) oder das Flugblatt mit der Frage: „Was der Deutsche gesät, Soll das der Pole ernten?“ (Format $16 \mathrm{~cm}$ $\times 24 \mathrm{~cm}$ ). Kurze, knapp formulierte Aussagen verlangen vom Rezipienten wesentlich weniger Aufmerksamkeit und Konzentration als umfangreiche Texte mit vielen Zahlenangaben; deshalb wurden sie zu einer beliebten plebiszitären Mitteilungsform - allerdings nur in prodeutschen Kreisen.

9 Die drei Parallelfragen, die sich auf die Wirtschaft, die Kirche und die Angliederung an Polen beziehen, fügen sich zu einer eigenartigen Serie zusammen. Eine derartige Aufbereitung der Texte bewirkt, dass zwischen den ephemeren Drucken, die von zwei gegnerischen Parteien verbreitet werden, ein Dialog entsteht, wobei die Ephemera als Träger von Stimmen in der Debatte funktionieren.

10 Das Flugblatt mit dem Dernburg-Zitat (nur in deutscher Fassung vorhanden) hat die Ausmaße $16 \mathrm{~cm} \times 24$ $\mathrm{cm}$. In einem einzigen Satz gemahnt es alle Oberschlesier an ihre Pflicht, wobei es ein religiöses Motiv für Persuasionszwecke verwendet: „Alle aus Oberschlesien gebürtigen Deutschen haben die Pflicht, diese Reise zu tun, und wenn sie noch beschwerlicher würde als der Gang nach Bethlehem.“

11 Das (nur deutschsprachige) Flugblatt mit dem Pfeiffer-Zitat hat ein Format von $15,5 \mathrm{~cm} \times 24,5 \mathrm{~cm}$ und besteht aus zwei Absätzen, wobei der erste Absatz eine Reihe von Fragen enthält (z.B.: „Soll die deutsche Sprache in Oberschlesien weiterklingen oder soll Gesetz und Satzung dort in fremder Zunge gegeben werden?"), wohingegen der zweite Absatz mit einer Ankündigung beginnt: „Auf diese Fragen soll der Abstimmungstag die Antwort geben." 
Im gesamten Korpus fallen des Weiteren Ephemera auf, die Text und Bild kombinieren. Meist handelt es sich dabei um satirische oder zu Anschauungszwecken eingesetzte Zeichnungen: Ein Bild soll den im Text angesprochenen Sachverhalt verdeutlichen. Vornehmlich wird ein (Größen-)Verhältnis, z.B. eine bestimmte Eigenschaft des beschriebenen Phänomens, symbolisch veranschaulicht. Dieses Verfahren kommt in Drucken der beiden Streitparteien zum Einsatz, wenn wirtschaftliche Daten verglichen werden. Als Beispiel sei ein Flugblatt angeführt, das - in polnischer und deutscher Fassung - zur Stimmabgabe für Polen aufruft. Der Text trägt die zweisprachige Überschrift: „Ile nafty wydobywa się rocznie w Polsce, a ile w Niemczech?“ (dt. Parallelfassung: „Wieviel Petroleum liefert Polen und wieviel Deutschland?"). Darunter ist ein großes Fass zu sehen, das wie folgt beschrieben wird: „Polska dostarcza rocznie 1087 tysięcy ton nafty“ (dt. Parallelfassung: „Polen liefert jährlich 1087000 Tonnen Petroleum“), daneben - ein acht Mal kleineres Fass mit dem Text: „W Niemczech wydobywa się rocznie tylko 138 tysięcy ton nafty“ („In Deutschland wird jährlich nur 130000 Ton. Petroleum gewonnen“). Das Anschauungsbild wird dazu noch explizit untertitelt:

\begin{tabular}{|l|l|}
\hline \multicolumn{1}{|c|}{ Polnisch } & \multicolumn{1}{|c|}{ Deutsch } \\
\hline „Polska kraj bogaty w liczne skarby ziemi, posiada & „Polen hat neben vielen anderen Bodenschätzen auch \\
nieprzebrane zapasy nafty. Polska ma beczkę 8 razy & unerschöpfliche Naphta-Vorräte. In Polen ist das Fass \\
większą niż Niemcy. Czy chcesz być tam, gdzie beczka & 8 mal grösser als in Deutschland! Willst du dorthin \\
jest mniejsza? Bądź mądry i głosuj za Polską!“ & gehen, wo das Fass kleiner ist? Sei klug und stimme für \\
& Polen!“ [Schreibweise wie im Original]
\end{tabular}

Diesem Gestaltungsmuster folgen noch weitere Drucke. Die Frage in der Überschrift eines zweisprachigen Flugblatts: „Ile siana łąkowego straciły Prusy?“ (dt. Parallelfassung: „Wieviel Wiesenheu hat Preussen verloren?", Abb. 2) wird durch die Abbildung von zwei mit Heu beladenen Fuhrwerken beantwortet, deren Größenverhältnis verdeutlichen soll, wie viel Heu vor dem Ersten Weltkrieg im Vergleich zur Gegenwart in Preußen hergestellt wurde (der Druck datiert aus dem Jahre 1920 oder 1921). Auf einem Flugblatt, das den Titel „Straty Niemiec w lasach i drzewie“ (dt. Parallelfassung: „Deutschlands Verlust an Wald und Holz“) trägt, sind unterschiedlich große Holzstücke abgebildet, neben denen jeweils ein kurzer Text (auf Polnisch und auf Deutsch) mit Zahlenangaben steht. Auch prodeutsche Drucke verwenden Anschauungsbilder. So wurde beispielsweise auf einem Flugblatt eine Tabelle abgedruckt, in der Schweine unterschiedlicher Größe abgebildet sind. Die Statistik in der Tabelle antwortet auf die Titelfrage: „Skądże pochodzi słonina?“ (dt. Parallelfassung: „Woher kommt der Speck?“, Abb. 3). Bei den aufgezählten Ländern: Deutschland, Russland, Rumänien und Ungarn sind große Schweine zu sehen, während das unterste Bild des "polnischen Schweins“ winzig klein ist; diese bildhafte Zusammenstellung soll das Volumen der Speckproduktion suggestiv veranschaulichen. ${ }^{12}$

12 Die Zahlen auf dem Flugblatt sehen wie folgt aus: Deutschland - 21 Mio. Schweine, Russland 12 Mio., Rumänien - 1,75 Mio., Ungarn - 7,5 Mio., Polen - 0,5 Mio. 


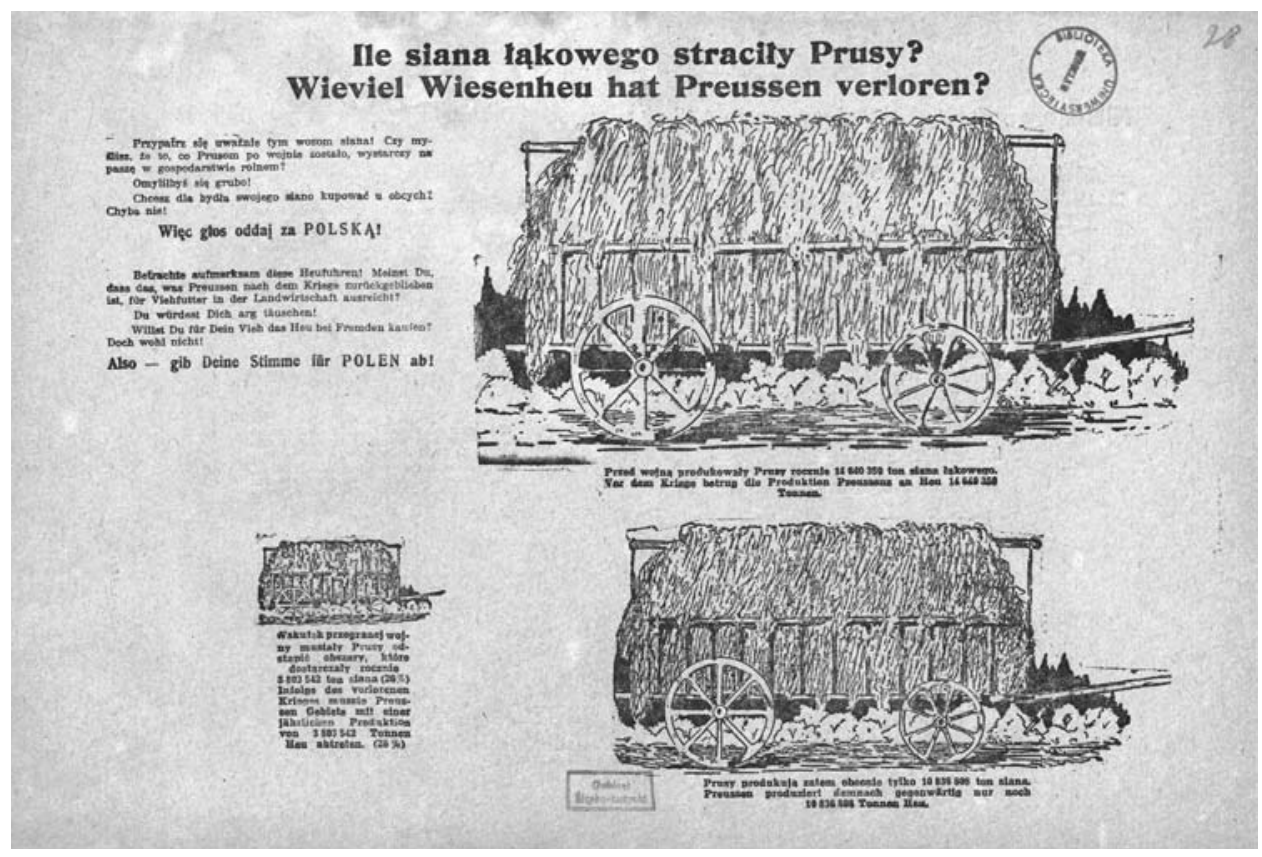

Abb. 2. Flugblatt „Ile siana łąkowego straciły Prusy? / Wieviel Wiesenheu hat Preussen verloren?“

Die Größenverhältnisse, die der Autor der Botschaft vermitteln will, sind auch auf einem anderen zweisprachigen prodeutschen Druck mit der Überschrift: „Górnoślązacy! Jakie będą w przyszłości podatki?“ (dt. Parallelfassung: „Oberschlesier! Wie wird’s mit den Steuern?“) veranschaulicht. Auf dem oberen Teil des Flugblatts sind zwei Männer in zwei Spalten einer Tabelle abgebildet. Der Mann links hält ein Päckchen unter dem Arm, der Mann rechts ist im Begriff, unter der Last von mehreren Paketen zusammenzubrechen. Die Zeichnung wird folgendermaßen erläutert:

\begin{tabular}{|c|c|}
\hline Polnisch & Deutsch \\
\hline $\begin{array}{l}\text { „Górnoślązak po stronie pruskiej: pomaga ponosić cię- } \\
\text { żary wojenne niemieckie. Jest to porządna paczka - ale } \\
\text { jeszcze będzie można pokroczyć naprzód!‘ } \\
\text { Górnoślązak po stronie polskiej: pomaga ponosić cię- } \\
\text { żary polskie, okrom tego część ciężarów wojennych nie- } \\
\text { mieckich, austriackich i ruskich., Cztery ciężkie paczki } \\
\text { - nie, z takim ciężarem nie można daleko postępować!“ }\end{array}$ & $\begin{array}{l}\text { „Der Oberschlesier auf preußischer Seite: er trägt mit } \\
\text { an den deutschen Kriegslasten. ,Ein tüchtiges Päckchen } \\
\text { - aber man kommt schon vorwärts!' } \\
\text { Der Oberschlesier auf polnischer Seite: er trägt die } \\
\text { polnischen Steuerlasten, außerdem einen Teil der deut- } \\
\text { schen, der österreichischen und der russischen Kriegs- } \\
\text { schulden. ,Vier schwere Lasten - nein, damit komme } \\
\text { ich nicht weit!““ }\end{array}$ \\
\hline
\end{tabular}

Die beiden eingerahmten Bilder mit dem begleitenden Text, die durch Anführungsstriche markierten Aussagen der abgebildeten Gestalten - all diese Eigenschaften erinnern an einen Comic. Im Grunde genommen macht die dargestellte Sequenz der beiden Bilder eine vollständige Botschaft aus und ist nicht lediglich eine Ergänzung zum abgedruckten Text. 


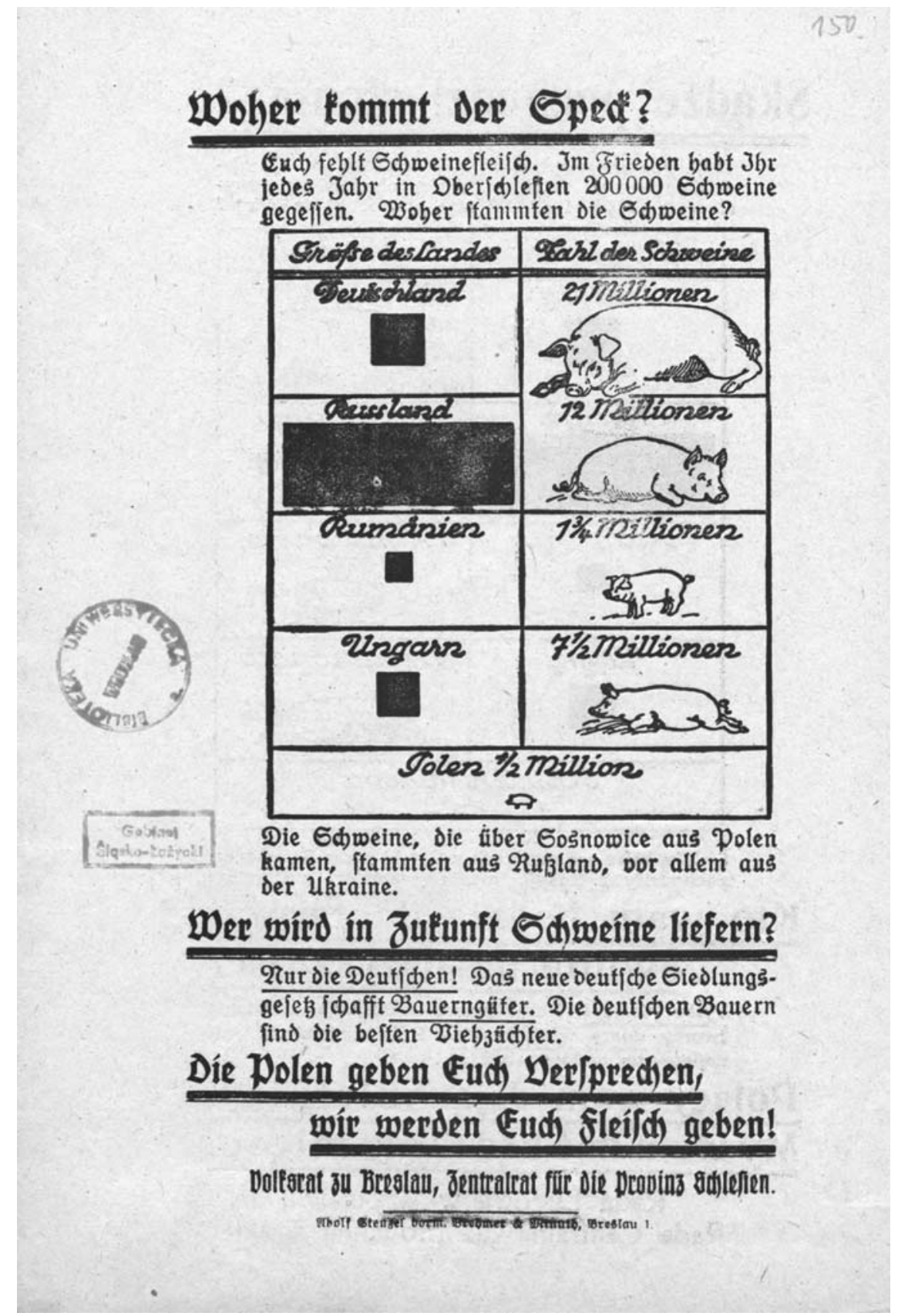

Abb. 3. Flugblatt „Woher kommt der Speck?“ (polnische Fassung auf der Rückseite) 
Typisch für ein Comic ist, dass eine Reihe von beschrifteten Bildern eine „lineare intermediale Erzählung" ergibt (vgl. ŁoJas 2014: 211); dies ist bei der hier angeführten kurzen Geschichte von der Steuerbelastung sicherlich der Fall.

Satirische Zeichnungen, die die plebiszitären Drucke so abwechslungsreich erscheinen lassen, waren auf der polnischen Seite besonders beliebt. Es handelt sich dabei vorwiegend um karikatureske Darstellungen von Personen oder Szenen, die die verspotteten Phänomene, Eigenschaften und Verhaltensweisen symbolisch wiedergeben. Eines der zweisprachigen satirischen Flugblätter trägt die Überschrift „Kto głosuje za Niemcami ?“(dt. Parallelfassung: „Wer stimmt für Deutschland?") und stellt vier stark überzeichnete Figuren in einer Umarmung dar. Die Beschriftung der Figuren gibt die Antwort auf die Titelfrage:

\begin{tabular}{|l|l|}
\hline \multicolumn{1}{|c|}{ Polnisch } & \multicolumn{1}{|c|}{ Deutsch } \\
\hline $\begin{array}{l}\text { „1.Żydowski szyber (paskarz); 2. Kapitalista, ciemięzca } \\
\text { ludu górnośląskiego; 3. Magnat, co ograbił was z ziemi; } \\
\text { 4. Idiota." }\end{array}$ & $\begin{array}{l}\text { "1. Der jüdische Schieber; 2. Der Kapitalist, der } \\
\text { Bedrücker des oberschl. Volkes; 3. Der Grossgrundbe- } \\
\text { sitzer (Junker) der Euch den Acker raubt; 4. Der Idiot." }\end{array}$ \\
\hline
\end{tabular}

Zu den Drucken, die durch ihre graphisch ansprechende Gestaltung auffallen, zählen auch zeichnerische Darstellungen von bestimmten Situationen und Genre-Szenen. Auf einem der zweisprachigen prodeutschen Drucke ist beispielsweise zu sehen, wie ein Offizier einem erschrockenen Mann, hinter dem sich dessen Frau mit Kind auf dem Arm versteckt, den Einberufungsbefehl überreicht. Diese Szene kommentiert folgender Text:

\begin{tabular}{|l|l|}
\hline \multicolumn{1}{|c|}{ Polnisch } & \multicolumn{1}{|c|}{ Deutsch } \\
\hline „W Polsce wojna na włosku! Zaciągająjuż najmłodszych & „In Polen droht der Krieg! Die jüngsten Jahrgänge \\
rekrutów! Pójdziesz więc na front! A potem kulka & werden eingezogen! Du kommst also an die Front! \\
w łeb! Zgnijesz jako trup w dole!” & $\begin{array}{l}\text { Eine Kugel macht Deinem Leben ein Ende! [...]dia- } \\
\text { lich [unleserlich, M.Ś.]. Wirst Du im Schützengraben } \\
\text { umkommen!“ }\end{array}$ \\
\hline
\end{tabular}

Botschaften dieser Art, die von Bildern bzw. Zeichnungen Gebrauch machen, lassen die hier behandelten Ephemera in die Nähe von anderen Formen rücken: der publizistischen Presse (dies gilt insbesondere für Drucke mit Zeichnungen, die Personen oder Sachverhalte verspotten sollen) oder des Plakats - eines Genres, das im ideologischen Kampf mit Vorliebe funktionalisiert wird (vgl. KaRPOwICZ 2014: 346). ${ }^{13}$

13 Anschlagzettel, die vor der Volksabstimmung angefertigt wurden, unterscheiden sich wesentlich von großformatigen, farbig gedruckten Plakaten im heutigen Sinne des Wortes. Allerdings sind sie auch von sonstigen plebiszitären Kommunikationsformen weit entfernt - etwa von großen, dicht bedruckten Papierbögen ohne Graphik, die eine aufmerksame Lektüre erforderten. Das Hauptmerkmal eines Plakats sei, so KARPOwICZ (2014: 345), nicht seine äußere Gestaltung oder Struktur, sondern seine Funktion, die sich auf die visuelle Gestalt des Plakats auswirkt - wobei Plakate dazu bestimmt seien, im öffentlichen Raum ausgehängt und massenweise verbreitet zu werden. Es sei das Merkmal des Genres Plakat, dass es den Blick des Betrachters fesseln und eine Wirkung entfalten soll (vgl. ebd.). Diese Funktion kommt auch den graphisch aufwendig gestalteten plebiszitären Drucken zu. 


\section{Sprachliche Mittel in den plebiszitären Drucken}

Die mit viel graphischem Aufwand gestalteten Ephemera treten zwar vor dem Hintergrund des Gesamtkorpus deutlich hervor, machen jedoch nicht dessen Großteil aus. In der überwiegenden Mehrheit der Fälle rührt die persuasive Kraft der Botschaft allein von der Sprache her. Was die Wirksamkeit der Botschaft fördert, sind einerseits verbale Mittel, die klare Werturteile enthalten, andererseits die Textsegmentierung, die eine effektive Rezeption der wichtigsten Inhalte erleichtert.

Das vornehmliche Ziel sämtlicher ephemerer Drucke, die vor der Volksabstimmung kolportiert wurden, bestand darin, die Oberschlesier für die in den Drucken entfaltete Sicht der Realität zu gewinnen und das Verhalten der Wähler zu steuern. Da es in diesem Konflikt zwei Parteien gab, kommt in den analysierten Texten eine dichotomische Gegenüberstellung: „wir vs. die anderen" deutlich zum Tragen. Dabei handelt es sich um eine konstruierte Opposition, da der Großteil der damaligen Bevölkerung Oberschlesiens - Polen, Deutsche, Tschechen kein ausgeprägtes nationales Bewusstsein besaß (vgl. CzUBí́sKi 2002: 102).

Was die Vermittlung von Werturteilen anbelangt, so zeichnen sich die propolnischen Aussagen dadurch aus, dass sie im Vergleich zu den prodeutschen Texten emotional stärker besetzt sind. Die Polen betonen in ihrer Selbstbeschreibung die Zugehörigkeit zu Oberschlesien. Sie formulieren etwa folgende Selbstdefinitionen:

In einsprachigen Drucken (nur auf Polnisch):

- „polski lud górnośląski” [sinngemäße dt. Übers.: ,das polnische Volk Oberschlesiens'];

- „dawny gospodarz tej ziemi” [sinngemäße dt. Übers.: ,der alte Herrscher dieses Landes'];

- „prawy właściciel” [sinngemäße dt. Übers.: ,der rechtmäßige Eigentümer'];

In zweisprachigen Drucken:

- „jesteśmy panami Górnego Śląska“ (dt. Parallelfassung: „Wir sind die Herren Oberschlesiens").

Die Deutschen hingegen werden in den propolnischen Drucken als ungebetene Gäste, geradezu als Besatzer dargestellt:

In einsprachigen Drucken (nur auf Polnisch):

- „zbiry niemieckie” [sinngemäße dt. Übers.: ,deutsche Banditen']

- „wrogie prusactwo” [sinngemäße dt. Übers.: ,das feindliche Preußentum']

In zweisprachigen Drucken:

\begin{tabular}{|l|l|}
\hline \multicolumn{1}{|c|}{ Polnisch } & \multicolumn{1}{c|}{ Deutsch } \\
\hline „obcy przybysze“ & „fremde Eindringlinge“ \\
\hline „obcy najeźdźca“ & „fremder Unterjocher" \\
\hline „brutalny wyzyskiwacz“ & „brutaler Aussauger“ \\
\hline
\end{tabular}


Selbst scheinbar wertneutrale Ausdrücke werden in einen negativen Kontext eingebettet, z.B. (in einem zweisprachigen Flugblatt) die mit Ausbeutung assoziierten „magnaci niemieccy i rząd pruski“ (dt. Parallelfassung: „die deutschen Magnaten und die preussische Regierung“). Die Zeit der deutschen Dominanz wird als „niemiecka niewola“ (dt. Parallelfassung: „deutsche Unfreiheit“) bezeichnet, die Rede ist auch von „okowy, które was i waszych Ojców więziły“ (dt. Parallelfassung: „Ketten [...], welche Euch und Eure Väter gedrückt haben“). Auch die bevorstehende Volksabstimmung wird intensiv mit Werten besetzt und von Autoren der propolnischen einsprachigen Drucke etwa mit folgenden Phrasen beschrieben:

In einsprachigen Drucken (nur auf Polnisch):

- ta wielka, z utęsknieniem wyczekiwana chwila dziejowa” [sinngemäße dt. Übers.: ,dieser große, herbeigesehnte historische Augenblick'];

- „przywrócenie spokoju i porządku na Górnym Śląsku” [sinngemäße dt. Übers.: ,die Wiederherstellung von Ruhe und Ordnung in Oberschlesien'];

- „ „święty bój” [sinngemäße dt. Übers.: ,der heilige Kampf'].

Im zweisprachig abgedruckten Aufruf von Wojciech Korfanty wird der Abstimmungstag selbst als Gelegenheit dargestellt, „das Joch der hundertjährigen preussischen Knechtschaft von seinen Schultern [zu] schütteln“ (polnische Parallelfassung: [okazja do] „zrzucenia jarzma wiekowej niewoli pruskiej”), sowie als „dzień walnej bitwy o szczęście i wolność naszą, o przyszłość dzieci, wnuków i wszystkich po nas następujących pokolen' “ (dt. Parallelfassung: „Der Tag der Entscheidungsschlacht um unser Glück und unsere Freiheit, um die Zukunft unserer Kinder, Enkel und allen kommenden Geschlechter"). In einem Flugblatt mit dem nur auf Polnisch abgedruckten Aufruf von General Józef Haller werden dem Tag des Plebiszits Attribute wie „uroczysty i wiekopomny” (sinngemäß: ,feierlich und unvergesslich') zugeschrieben.

Die prodeutschen Drucke hingegen konzentrieren sich nicht auf den Tag der Volksabstimmung, sondern vielmehr auf die imaginierte Zukunft der Region für den Fall, dass sich die Bevölkerung für eine Angliederung an Polen ausspricht. Eines der zweisprachigen Flugblätter unter dem Titel „Śmierć idzie z Polski na Górny Śląsk!“ (dt. Parallelfassung: „Der Todeszug durch ein polnisches Oberschlesien!") schildert die aktuelle Stimmungslage der oberschlesischen Bevölkerung, den Konflikt zwischen den Polen und den Bolschewiken und anschließend die Perspektive, dass oberschlesische Männer zum Wehrdienst einberufen werden. Die Textbotschaft hat einen stark persuasiven Charakter:

\begin{tabular}{|l|l|}
\hline \multicolumn{1}{|c|}{ Polnisch } & \multicolumn{1}{|c|}{ Deutsch } \\
\hline "Górnoślązaku! To cię czeka, gdyby Górny Śląsk przy- & „Oberschlesier! Das wird Dein Los sein, wenn Ober- \\
padł do Polski. Kulka w teb i zgnijesz w dole! W Niem- & schlesien zu Polen fallen sollte: Ein Schuß in den Kopf \\
czech nie ma już przymusu wojskowego. Wybieraj & und der Tod im Schützengraben! In Deutschland ist \\
więc: W Niemczech życie! W Polsce śmierć! Głosuj & die Wehrpflicht abgeschafft. Wähle also: In Deutsch- \\
za Niemcami!“ & $\begin{array}{l}\text { land Leben! In Polen den Tod! Stimme darum für } \\
\text { Deutschland!“ }\end{array}$ \\
\hline
\end{tabular}


Die in dieser Passage prägnant ausgedrückte Dichotomie wird zusätzlich durch die Lexik und die Ausrufezeichen verstärkt. Ähnliche Mittel kommen in einem weiteren zweisprachigen Flugblatt zur Anwendung, das die Reaktionen auf einen Aufruf von Wojciech Korfanty darstellt. In diesem Text ist die Rede davon, dass die Worte des polnischen Plebiszitkommissars Ausdruck des „Mut[s] der Verzweiflung“ (poln. Parallelfassung: „odwag[a] rozpaczy“) seien sowie einen Versuch darstellen, zu retten, „was zu retten ist“ (poln. Parallelfassung: „co jeszcze uratować można“). In demselben zweisprachigen Flugblatt ist weiter Folgendes zu lesen:

\begin{tabular}{|l|l|}
\hline \multicolumn{1}{|c|}{ Polnisch } & \multicolumn{1}{|c|}{ Deutsch } \\
\hline „Nie dajcie się zbałamucić! Według traktatu poko- & "Laßt Euch nicht beirren! Weder die polnische, \\
jowego ani polski ani niemiecki rząd nie mają prawa & noch die deutsche Regierung darf laut Friedensver- \\
kogokolwiek za przestępstwa polityczne ukarać! & trag jemandem auch nur ein einziges Haar krümmen \\
$\begin{array}{l}{[. .] \text { Tylko dla rabusiów, złodziei i morderców nie }} \\
\text { będzie miejsca na Górnym Śląsku, gdy przy Niem- } \\
\text { cach pozostanie." }\end{array}$ & $\begin{array}{l}\text { Diegen politischer Vergehen! [...] Nur für Räuber, } \\
\text { schlesien kein Platz sein." }\end{array}$ \\
\hline
\end{tabular}

Wie hier deutlich wird, versuchten beide Parteien mit ähnlicher Verbissenheit, die Adressaten von der Richtigkeit der eigenen Meinung zu überzeugen. Die propolnischen Flugblätter scheinen im Vergleich zu den prodeutschen Schriften mehr Pathos zu enthalten, außerdem berufen sie sich häufig auf abstrakte Werte. In den prodeutschen Ephemera tritt das Pathos in den vorhin genannten aphoristischen und gereimten Formen in Erscheinung.

In den propolnischen zweisprachigen Drucken fällt die Unmittelbarkeit des Ausdrucks auf, die bereits in den Überschriften zum Tragen kommt, z.B.:

\begin{tabular}{|l|l|}
\hline \multicolumn{1}{|c|}{ Polnisch } & \multicolumn{1}{|c|}{ Deutsch } \\
\hline $\begin{array}{l}\text { „Albo świetna przyszłość i dostatek - albo } \\
\text { wywłaszczenie i dziadowski kostur!” }\end{array}$ & „Entweder eine glänzende Zukunft und Wohlhaben- \\
heit, oder Enteignung und Bettelstab!“
\end{tabular}

In einem der propolnischen zweisprachigen Flugblätter werden die Verbindlichkeiten Deutschlands gegenüber den Entente-Staaten aufgezählt. Es wird im Detail ausgeführt, wie viel Stück Vieh die Deutschen an Frankreich, Belgien und andere Länder abzugeben haben. Die Autoren des Flugblatts sprechen den einzelnen Mitbürger an:

\begin{tabular}{|l|l|}
\hline \multicolumn{1}{|c|}{ Polnisch } & Deutsch \\
\hline „Rolniku Górnośląski! Ostatnią krowę i kozę wyciągną & „Oberschlesischer Landwirt! Die letzte Kuh und die \\
Ci z obory! Wiesz przecie z czasów wojny, że urzędy & letzte Ziege wird man aus deinem Stalle nehmen. Es ist \\
pruskie oszczędzają dwory niemieckie. I tobie, Robot- & Dir vom Kriege bekannt, dass die preussischen Behör- \\
niku Górnośląski, brakować będzie kropli mleka dla & den den Viehbestand des preussischen Junkers schonen. \\
dziecka i mięsa dla odżywienia się po ciężkiej pracy. & Und dir, oberschlesischer Arbeiter, wird für deine Kin- \\
Ratuj się przed nędzą, ratuj swój inwentarz i głosuj za & der kein Tropfen Milch zu haben sein, und kein Fleisch \\
Polską!” & zu deiner Ernährung nach schwerer Arbeit. Rette dich \\
& vor Elend, rette dein Inventar und stimme für Polen!“ \\
\hline
\end{tabular}


Die Botschaft, verstärkt durch Ausrufe und eine Synekdoche, ergänzt die detaillierten Zahlenangaben auf der Rückseite des Flugblatts. Außerdem appelliert der Autor an die Lebenserfahrung des Rezipienten („Wiesz przecie z czasów wojny“, dt. Parallelfassung: „Es ist Dir vom Kriege bekannt“) und bezieht sich auf die Realien seines Alltags („po ciężkiej pracy“, dt. Parallelfassung: „nach schwerer Arbeit“). Durch diese rhetorische Strategie erscheint der Sender der Botschaft in der Position einer Person, die mit den Lebensverhältnissen der Oberschlesier bestens vertraut ist.

Dennoch gibt es viele Ähnlichkeiten zwischen den Ephemera, die auf den beiden gegnerischen Seiten entstanden. Eine der Analogien ist die Berufung auf Autoritäten, die mit ihrer Macht den Text unterstützen und legitimieren. Die polnische Seite druckte die Aufrufe des Generals Józef Haller ab, der sich mit folgenden emotionalen Worten an die Oberschlesier wandte: „Głosować będziecie nie tylko za samych siebie, ale za dzieci, za wnuki, za przyszłe pokolenia" [nur in polnischer Fassung vorhanden; sinngemäß: , Ihr werdet Eure Stimme nicht nur in eurem eigenen Namen, sondern auch im Namen eurer Kinder, Enkel und aller kommenden Geschlechter abgeben']. ${ }^{14}$ Außer Hallers Text wurden auch der (oben bereits erwähnte) Aufruf des polnischen Plebiszitkommissars Wojciech Korfanty sowie die Worte von Wilhelm Kloske, dem Weihbischof des Bistums Gnesen-Posen, auf Flugblättern verbreitet. Alle drei Autoren brachten die Glaubensfragen zur Sprache, die in den Texten der polnischen Seite häufig vorkommen. In den propolnischen Drucken wird die katholische Religion der evangelischen gegenübergestellt - eine Opposition, die ein wesentliches Argument in der Diskussion vor der Volksabstimmung lieferte. Auf einem nur auf Polnisch verfassten Flugblatt, das die Apostrophe an das ,Katholische Volk Oberschlesiens („Katolicki Ludu Górnośląski!”) in der Überschrift führt, wird der einzelne Leser angesprochen:

- „Czy trudno Ci jest zgadnąć, gdzie grozi Ci utrata wiary ojców Twoich - w Niemczech czy w Polsce? Dziecko Twoje już to dobrze rozumie, że germanizacja to protestantyzacja! [...] Walka o Śląsk Górny jest zarazem walką kościoła katolickiego z wiarą luterską." [sinngemäße dt. Übers.: ,Fällt es Dir schwer zu erraten, wo Dir die Gefahr droht, den Glauben Deiner Väter zu verlieren: in Deutschland oder in Polen? Bereits Dein Kind kann begreifen, dass die Germanisierung der Protestantisierung gleichkommt! [...] Der Kampf um Oberschlesien ist zugleich ein Kampf der katholischen Kirche mit dem lutherischen Glauben.] ${ }^{15}$

14 Im polnischen Text, der mit der Apostrophe an die Schlesier („Ślązacy!”) beginnt, lesen wir weiter: „Dwadzieścia pięć milionów braci niecierpliwie wyczekuje godziny swego z wami złączenia. Razem na dolę i niedolę! Ufajcie! Wasza krzywda jest naszą krzywdą. Czekamy na wasz czyn, głosujcie jak Wam każe Bóg i Ojczyzna” [sinngemäße dt. Übers.: ,Fünfundzwanzig Millionen Brüder erwarten mit Ungeduld die Stunde, in der sie mit euch vereinigt sind. Zusammen im Glück und Unglück! Habt Vertrauen! Euer Leid ist unser Leid. Wir warten auf eure Tat, wählt, wie es euch Gott und das Vaterland gebieten.']

15 Über die Verbundenheit mit dem katholischen Glauben, die in polnischen plebiszitären Drucken zum Ausdruck kommt, schreibt HeSKa-KwaśnIEWICZ (2006: 105), die in ihrem Korpus dieselben Formulierungen identifiziert. 
Autoren der prodeutschen Drucke berufen sich hingegen u.a. auf die Autorität von Goethe: In der vierseitigen Flugschrift „Einladung zur Abstimmung “ (mit dem Untertitel: „Die Heimat ruft!") befindet sich ein auf den 4. September 1790 datiertes Gedicht Goethes. Das Datum ist nicht ohne Relevanz, denn an diesem Tag besichtigte Goethe zusammen mit dem Herzog Carl August von Sachsen-Weimar-Eisenach das Bergwerk in Tarnowitz (Tarnowskie Góry). Ein weiteres Beispiel dafür, wie die Macht von Autoritäten genutzt wurde, sind die bereits angesprochenen Flugblätter, in denen Zitate aus den Schriften von Maximilian Pfeiffer und Bernhard Dernburg verbreitet wurden.

Zum Schluss seien noch kurz die Parolen auf zahlreichen Anschlagzetteln erwähnt, die die Haltung der Rezipienten wesentlich mitprägten. Parolen und Slogans sind besonders tragfähige Formen von Textbotschaften, sie drücken die Intention des Senders kurz und bündig aus und beeinflussen die Einstellungen sowie die Verhaltensweisen des angesprochenen Publikums. In den plebiszitären Drucken sind die Aufrufe: „Głosuj za Polską!“ [in einem einsprachigen Flugblatt, sinngemäße dt. Übers.: ,Stimme für Polen!'] und „Głosuj za Niemcami!“ (zweisprachig, dt. Parallelfassung: „Stimme für Deutschland!“) am häufigsten zu lesen. Der Appell an die Rezipienten, an der Abstimmung teilzunehmen, steht in manchen Fällen am Ende des Flugblatts, meist aber ist er Bestandteil von ausgebauten Parolen, z.B. in den prodeutschen zweisprachigen Texten:

\begin{tabular}{|l|l|}
\hline \multicolumn{1}{|c|}{ Polnisch } & \multicolumn{1}{c|}{ Deutsch } \\
\hline „Miejcie się na baczności!” & „Augen auf!“ \\
\hline „My nie chcemy do Polski!” & „Wir wollen nicht zu Polen!“ \\
\hline „Chcemy zostać Niemcami albo zginiemy!” & „Wir bleiben Deutsche oder wir sterben!“ \\
\hline „Więc rozważaj sobie! Nie daj się skłamać!” & „Denkt nach! Laßt Euch nicht belügen!“ \\
\hline
\end{tabular}

In den propolnischen zweisprachigen Drucken gestalten sich die Parolen zu langen, mehrgliedrigen Reihen, z.B.:

\begin{tabular}{|l|l|}
\hline \multicolumn{1}{|c|}{ Polnisch } & \multicolumn{1}{|c|}{ Deutsch } \\
\hline $\begin{array}{l}\text { „Precz z jednoroczną pracą przymusową! Precz } \\
\text { z nowoczesną pańszczyzną niemiecką! Precz z rzą- } \\
\text { dami pruskimi i niemieckimi z Górnego Śląska! } \\
\text { Bądźmy wolnym narodem i głosujmy za Polską!” }\end{array}$ & $\begin{array}{l}\text { Arbeitspflicht! Nieder mit der neugeplanten } \\
\text { Knechtstaft und Fronarbeit! Weg mit dem Preus- } \\
\text { sentum aus Oberschlesien! Oberschlesier! Bleibt ein } \\
\text { freies Volk und stimmt für Polen!“ }\end{array}$ \\
\hline „Baczność! Nie dajmy sfałszować plebiscytu!” & $\begin{array}{l}\text { "Achtung! Wir lassen uns die Abstimmung nicht } \\
\text { fälschen!“ }\end{array}$ \\
\hline „Precz z Berlinem! My głosujemy za Polską!” & "Los von Berlin! Wir stimmen für Polen!“ \\
\hline
\end{tabular}

\section{Fazit}

Es empfiehlt sich, die plebiszitären Drucke aus einer ganzheitlichen Perspektive zu untersuchen, da sie dann als Botschaftsträger mit besonders hoher persuasiver Kraft erscheinen. Betrachtet man die in der Universitätsbibliothek in Wrocław archivierten Ephemera als einheitliches Korpus von Texten, die dasselbe Ziel, nämlich den Sieg der jeweils eigenen Partei 
in der Volksabstimmung verfolgen, so nehmen sie sich als Medien mit einem beabsichtigten Einfluss auf die Meinungen und Verhaltensweisen einer bestimmten Menschengruppe aus, in diesem Fall: der Bevölkerung des Abstimmungsgebiets.

Die Einzigartigkeit der besprochenen Ephemera beruht in erster Linie auf (1) der Synchronie der deutschen und der polnischen Botschaften. Mehr als die Hälfte der hier ausgewerteten 165 Drucke sind zweisprachig, wobei die beiden Sprachversionen sich sowohl inhaltlich als auch formal bzw. visuell in allen Fällen ähneln: Bei den Texten fällt nicht nur der ausgeprägte persuasive Gehalt, sondern auch der hohe Informationswert auf - besonders dort, wo komplexe wirtschaftliche oder politische Sachverhalte erklärt werden.

(2) Dennoch sind die Botschaften je nach den anvisierten Rezipienten relativ stark differenziert aufbereitet. Stilistische Unterschiede zwischen den prodeutschen und propolnischen Flugblättern machen sich besonders im Textaufbau und in der Form bemerkbar: Die prodeutschen Drucke berufen sich auf Autoritäten (durch Bezüge auf Aussagen von Dichtern und Politikern), während auf der propolnischen Seite Texte mit stark wertenden stilistischen Mitteln (etwa in den Überschriften) sowie satirische Kurzformen überwiegen.

(3) Darüber hinaus steht außer Frage, dass der Schauplatz des „Papierkriegs“, von dem die hier besprochenen Ephemera zeugen, die Region Oberschlesien war: ein zusammenhängender, wenn auch nach innen differenzierter Raum. In den ephemeren Drucken, die dem Plebiszit vorausgingen, wurden zwar auch weltgeschichtliche und überregionale Probleme angeschnitten - beispielsweise der polnisch-russische Konflikt oder die deutschen Reparationen nach dem Ersten Weltkrieg -, deren Thematisierung war der persuasiven Funktion jedoch untergeordnet. Der tatsächliche Adressat der Texte war hingegen die regionale Gemeinschaft, die über ihre Zugehörigkeit entscheiden sollte. Die Rezipienten wurden dabei paradoxerweise immer angesprochen, als ob unabhängig vom Ausgang der Wahl die eigene Identität unberührt bleiben würde. Die Rezipienten wurden dementsprechend stets als „Oberschlesier“ bezeichnet, nie als „Polen“ oder „Deutsche“. Zudem gibt es in den Texten Anspielungen auf das oberschlesische Traditionsgefühl und die oberschlesische Religiosität.

(4) Ein weiteres Merkmal, das von der Singularität der oberschlesischen Ephemera zeugt, ist ihre Dialogizität. Viele Flugblätter wirken wie Einblatt-Zeitungen, die nicht nur schlichte Informationen zu einem bestimmten Thema, sondern auch Kommentare zu Texten der Gegenpartei vermitteln. Beispielsweise beginnt ein zweisprachiges prodeutsches Flugblatt wie folgt: „Korfanty woła: Niemcom grozi jednoroczna przymusowa praca!“ (dt. Parallelfassung: „Korfanty ruft: den Deutschen droht die einjährige Arbeitspflicht!"), woran sich eine Polemik gegen die Worte des polnischen Plebiszitkommissars anschließt. Das bereits angeführte, zweisprachige propolnische Flugblatt mit dem Aufruf an den „oberschlesischen Landwirt“ („Rolniku Górnośląski!“) enthält wiederum folgenden Verweis: „Zob. Berliner Tageblatt z 4 grudnia 1920 Nr. 556“ (dt. Parallelfassung: „Siehe Berliner Tageblatt vom 4.XII.1920 Nr. 556").

(5) Das letzte Merkmal des untersuchten Korpus von Ephemera liegt in seinem breiten Wirkungskreis, einer großen Auflagenstärke sowie seiner massenweisen Verbreitung vor der Volksabstimmung. Eine Auflage von mehreren hunderttausend Druckexemplaren wirkt durchaus imposant. Auch die äußere Form der Flugblätter - das handliche Format, meist in etwa 
der Größe einer A4-Seite, der Einsatz von graphischen, oft satirischen Elementen - förderte ihre Wirksamkeit und verhalf ihnen dazu, breite Leserkreise zu erreichen und die öffentliche Meinung zu prägen. „Czytaj i podaj dalej!“(dt. Parallelfassung: „Lesen und weitergeben!“) dieses Schlagwort, das auf mehreren Drucken aus dem hier erschlossenen Korpus steht, zeugt am besten vom Verwendungszweck und von der persuasiven Kraft der ephemeren Drucke.

Aus dem Polnischen von Katarzyna Lukas

\section{Bibliographie}

\section{Quellenmaterial}

Ephemere Drucke aus der Universitätsbibliothek der Universität Wrocław, Sammlung von Ephemera der Schlesisch-Sorbischen Abteilung (Gabinet Śląsko-Łużycki), aufbewahrt in zwei Mappen:

- „Plebiscyt na Górnym Śląsku. Afisze i ulotki propagandowe propolskie” [Die Volksabstimmung in Oberschlesien. Propolnische Anschlagzettel und Propaganda-Flugblätter],

- „Plebiscyt na Górnym Śląsku. Afisze i ulotki propagandowe proniemieckie” [Die Volksabstimmung in Oberschlesien. Prodeutsche Anschlagzettel und Propaganda-Flugblätter].

\section{Sekundärliteratur}

Czubiński, Antoni (2002): Historia Polski 1864-2001 [Die Geschichte Polens 1864-2001]. Wrocław - Warszawa - Kraków: Ossolineum.

Goniewicz, Aleksandra (2001): Powstania śląskie 1919. 1920. 1921. Przewodnik po miejscowościach [Die Aufstände in Oberschlesien 1919. 1920. 1921. Ein Fremdenführer durch die Schauplätze]. Katowice: Centrum Dziedzictwa Kulturowego Górnego Śląska.

HeSKA-KwAŚNIEWICZ, Krystyna (1999): „Wyznanie narodowe Ślaska”. Teksty literackie i paraliterackie w drukach okresu powstań i plebiscytu na Górnym Ślasku [„Das nationale Glaubensbekenntnis Schlesiens". Literarische und paraliterarische Texte in den Drucken aus der Zeit der Aufstände und der Volksabstimmung in Oberschlesien]. Katowice: Wydawnictwo Uniwersytetu Śląskiego.

Heska-Kwaśniewicz, Krystyna (2006): Poetyka ulotek z okresu powstań i plebiscytu na Górnym Śląsku [Zur Poetik der Flugblätter aus der Zeit der Aufstände und der Volksabstimmung in Oberschlesien]. In: Migoń, Krzysztof / SKalska-Zlat, Marta / ŻBikowska-Migoń, Anna (Hg.): Druki ulotne i okolicznościowe - wartości i funkcje. Materiaty międzynarodowej konferencji naukowej, Wojnowice, 8-10 października 2004 [Ephemera und Gelegenheitsdrucke - Werte und Funktionen. Beiträge der internationalen wissenschaftlichen Konferenz in Wojnowice, 8.-10. Oktober 2004]. Wrocław: Wydawnictwo Uniwersytetu Wrocławskiego, 102-112.

Karpowicz, Agnieszka (2014): Plakat [Das Plakat]. In: Godlewski, Grzegorz (Hg.): Od aforyzmu do zinu. Gatunki twórczości stownej [Von Aphorismus bis Zine. Gattungen der Wortkunst]. Warszawa: Wydawnictwa Uniwersytetu Warszawskiego, 345-354.

KRZYK, Józef (2014): Wojna papierowa: powstania ślaskie 1919-1921 [Papierkrieg: die Aufstände in Oberschlesien 1919-1921]. Warszawa: Agora. 
Lis, Michał (2015): Powstania ślaskie i plebiscyt ze wspótczesnej perspektywy [Die Aufstände und die Volksabstimmung in Oberschlesien aus gegenwärtiger Perspektive]. Opole: Państwowy Instytut Naukowy - Instytut Śląski w Opolu.

Lis, Michał / DróżDż, Leokadia (Hg.) (2012): Plebiscyt i powstania ślaskie 1919-1921 - po 90 latach [Die Aufstände und die Volksabstimmung in Oberschlesien 1919-1921 - nach 90 Jahren]. Opole: Państwowy Instytut Naukowy.

ŁoJAS, Joanna (2014): Komiks [Das Comic]. In: GodlEwsKI, Grzegorz (Hg.): Od aforyzmu do zinu. Gatunki twórczości stownej [Von Aphorismus bis Zine. Gattungen der Wortkunst]. Warszawa: Wydawnictwa Uniwersytetu Warszawskiego, 211-220.

Zieliński, Władysław (1972): Polska i niemiecka propaganda plebiscytowa na Górnym Ślasku [Die polnische und die deutsche Propaganda im Vorfeld der Volksabstimmung in Oberschlesien]. Wrocław: Ossolineum.

\section{Nachschlagewerke mit Siglen}

EPŚ - HaWraneK, Franciszek (Hg.) (1982): Encyklopedia powstań ślaskich [Enzyklopädie der Aufstände in Oberschlesien]. Opole: Instytut Śląski w Opolu.

STM - PISAReK, Walery (Hg.) (2006): Stownik terminologii medialnej [Wörterbuch der MedienTerminologie]. Kraków: Universitas.

Abbildungen

Plebiszitäre Flugblätter aus Oberschlesien, aus den Sammlungen der Universitätsbibliothek der Universität Wrocław

(c) Universitätsbibliothek der Universität Wrocław 